\section{Potencialidades e desafios da participação em instâncias colegiadas dos sistemas de saúde: os casos de Itália, Inglaterra e Brasil}

\author{
Strengths and challenges of citizens' \\ participation in local health councils: \\ the cases of Italy, England, and Brazil
}

\author{
1 Centro de Ciências da \\ Saúde, Universidade \\ Estadual do Ceará, \\ Fortaleza, Brasil. \\ 2 Facultat de Lletres, \\ Universitat Rovira i Virgili, \\ Tarragona, España. \\ Correspondência \\ M. Serapioni \\ Centro de Ciências da \\ Saúde, Universidade \\ Estadual do Ceará. \\ Rua Artur Façanha 75, \\ apto. 604, Fortaleza, $C E$ \\ 60175-130, Brasil. \\ mauro_serapioni@yahoo.es
}

\begin{abstract}
This paper focuses on three models for citizens' participation in health (Italy, Great Britain, and Brazil). After discussing the strengths and weakness of the three experiences, the study presents a comparative analysis, highlighting convergences and variations in relation to the main characteristics of social participation in the health sector: (a) organization and composition of health councils; (b) functions played by citizens' representatives (decision-making, advisory, or social control or oversight); and (c) approaches to community participation. The paper then focuses on two critical points emerging from the analysis of experiences with community participation: the issue of representativeness and the difficulty experienced by representatives of health services users in influencing the decision-making by system managers.
\end{abstract}

Citizen Participation; Health Systems; Advisory Committees
Mauro Serapioni 1

Oriol Romaní 2

\section{Introdução}

Nos últimos vinte anos diferentes processos de mudança estão afetando a saúde. Embora se trate de processos heterogêneos nos conteúdos (científicos, éticos, normativos, organizacionais etc.) e nas perspectivas delineadas, quase todos evidenciam a necessidade de superar um sistema de saúde ainda incapaz de promover uma maior interação com seu ambiente social. Essa constatação levou muitos países a redefinirem a organização dos serviços sanitários e a colocarem no centro do sistema os beneficiários desses serviços. De fato, entre os diversos motivos aduzidos por governos de países tão diversos - tais como Alemanha, Brasil, Chile, Espanha, Itália, Portugal, Reino Unido, Suécia etc. - para apoiarem as reformas sanitárias, cabe mencionar a crescente insatisfação das pessoas com a qualidade da atenção 1,2,3.

Assim, ao longo da década de noventa observou-se um crescente interesse em promover a participação da população e reequilibrar a relação entre oferta e demanda de serviços de saúde. Hoje, ninguém nega que a participação é uma condição necessária para que una população melhore a sua saúde e sua qualidade de vida.

Apesar das boas intenções e de alguns louváveis esforços empreendidos, a participação ainda demora a entrar na práxis dos serviços. Muitos estudiosos têm evidenciado a existên- 
cia de uma contradição entre o discurso político (e, às vezes, até a retórica) sobre participação dos cidadãos e a prática das instituições de saúde ainda pouco sensível às contribuições do ambiente social 4,5. Entre os diversos motivos que podem explicar esse gap entre discurso e práxis, cabe enfatizar as diferentes maneiras de entender a participação em saúde. A falta de uma definição clara e compartilhada do conceito de participação é responsável pela ampla variedade de significados e de orientações ideológicas adotados nos diferentes contextos 6,7,8. O fornecimento de questionários aos usuários para averiguar seus níveis de satisfação, por exemplo, é geralmente considerado uma estratégia de participação. Porém, como argumenta Crouch 9 , nesse caso, trata-se de um "exercício muito pobre", se o objetivo é desenvolver um espaço de "cidadania dialógica" (p. 275). As pesquisas de mercado, acrescenta Pollock 10 (p. 536), “não podem absolutamente substituir um processo democrático, senão, a participação se torna um conceito sem sentido".

A partir dessas premissas, este artigo apresenta três modelos de participação em saúde os Comitati Consultivi Misti (Comitês Consultivos Mistos - CCM) da Itália, os Community Health Councils (Conselhos Comunitários de Saúde - CHC) da Inglaterra e os Conselhos Municipais de Saúde (CMS) do Brasil - evidenciando as características organizacionais, as potencialidades e os limites de cada um. Sucessivamente, será realizada uma análise comparativa das três experiências, destacando regularidade e variações em relação às principais dimensões da participação em saúde.

\section{Objetivos do estudo e método}

Nossa investigação pretende analisar a real efetividade desses sistemas de participação e, precisamente, visa responder às seguintes perguntas: (a) os usuários realmente utilizam os sistemas de participação existentes para expressar suas demandas e problemas? (b) as propostas dos representantes dos usuários são incorporadas nos processos de gestão dos serviços de saúde? (c) os fóruns de participação são lugares de representação de todos os cidadãos ou somente de alguns segmentos deles? (d) quais os modelos de participação mais efetivos para promover relações significativas entre sistema sanitário e associações da sociedade civil?

Através dos resultados das três experiências de participação, nosso estudo visa contribuir para a analise da relação entre sistema de saúde e cidadãos 11,12 e traçar possíveis caminhos para aprimorar o envolvimento de pacientes e usuários no âmbito da saúde.

Nossa análise refere-se a experiências desenvolvidas em diferentes contextos sócio-econômicos, culturais e políticos. Não é tarefa simples comparar fenômenos sociais como a participação dos cidadãos, que envolve dimensões estreitamente relacionadas à história das instituições políticas e ao desenvolvimento da sociedade civil. Para nos protegermos dos riscos de uma comparação que analisasse as propriedades sem ter na justa consideração os respectivos vínculos do contexto, desenhamos uma comparação de "estágios múltiplos" 13, articulada em duas fases: primeiro, longitudinalmente, para o estudo da evolução histórica dos sistemas de saúde dos três países e para identificar as possíveis inter-relações entre os órgãos de participação previstos, as respectivas propriedades e os relativos contextos; segundo, transversalmente, para a análise comparativa propriamente dita, descrevendo as regularidade e as variações referentes aos três sistemas de participação.

Para estudar o tema da participação social adotamos uma perspectiva de análise fenomenológica que nos permitiu entender a realidade em seus aspectos naturais e de nos aproximar o mais possível do ponto de vista de seus protagonistas: representantes dos usuários, profissionais e gerentes.

\section{A participação dos cidadãos no sistema sanitário da Região Emilia-Romagna, Itália}

\section{O processo de reforma do sistema de saúde italiano}

O Servizio Sanitario Nazionale (SSN) foi criado em 1978 para substituir um sistema de saúde fortemente fragmentado em mais de cem operadoras de planos e seguros. A reforma de 1978, pela primeira vez, introduziu a universalização da atenção à saúde e desenvolveu um processo de descentralização baseado nas autoridades regionais e locais. Sem dúvida, a introdução do novo SSN representou um grande avanço para os setores mais débeis da sociedade italiana; contudo o sistema mostrou, também, evidentes sinais de mau funcionamento e de ineficiência. O aumento da insatisfação por parte de diferentes setores da sociedade levou o Governo, por meio do Decreto Legislativo n. 502 de 1992, a modificar a reforma sanitária e introduzir um sistema de garantia da qualidade a ser avaliado também por parte dos usuários e 
não somente pelos gerentes e profissionais de saúde.

A Região Emilia-Romagna, pela Lei Regional n. 19 de 1994, tem aplicado o disposto pelo decreto acima mencionado, relativamente à participação dos cidadãos no âmbito do sistema de saúde. De fato, a lei regional prevê expressamente que as autoridades sanitárias dos distritos e dos hospitais ponham à disposição das associações dos usuários sedes adequadas para desenvolver sua atividade de representação e defesa dos direitos dos pacientes. Além disso, a lei recomenda a instituição dos CCM para o controle da qualidade da atenção.

\section{Objetivos e características organizacionais} dos Comitês Consultivos Mistos

Os CCM representam a instância institucional para dar voz às associações da sociedade civil a fim de garantir a correspondência dos serviços de saúde às exigências dos cidadãos. Reúnemse uma vez por mês e estão formados por representantes das associações de voluntariado, além de um componente minoritário designado pela autoridade de saúde, compreendendo administradores e profissionais. A outra característica dos CCM é a de serem consultivos, ou seja, expressam seus próprios pareceres, efetuam visitas e controles na estruturas sanitárias e sugerem propostas à gerência que, ao final das contas, mantêm toda a responsabilidade e autonomia da decisão 14 . Sua finalidade é verificar a qualidade da atenção na visão dos usuários. Devem, em outras palavras, observar os serviços de saúde com os olhos dos cidadãos.

\section{Resultados da investigação sobre os Comitês Consultivos Mistos}

A pesquisa, realizada no ano 2000, abrangeu todos os CCM da cidade de Bolonha e uma amostra de CCM das cidades de Ferrara, Imola e Modena. Foram entrevistados 35 informantes, entre coordenadores de CCM (representantes das associações de usuários), profissionais de saúde, gerentes, diretores e porta-vozes das organizações de tutela dos direitos dos pacientes. Foram ainda realizadas observações diretas durante as reuniões mensais dos CCM, no período de abril a julho. Em seguida, referimos os resultados do estudo, organizados em quatro áreas temáticas: (a) configuração organizacional dos CCM; (b) nível de participação dos representantes das associações; (c) influência das propostas dos CCM sobre os processos decisórios dos gerentes; (d) representatividade dos CCM.

\section{O modelo organizacional dos} Comitês Consultivos Mistos

Da análise da experiência dos primeiros cinco anos de vida dos CCM emergiu uma avaliação satisfatória da configuração organizativa dos comitês. Quase todos os informantes mencionaram o valor positivo desse órgão colegiado. A colaboração entre os membros dos diversos componentes do comitê representa, de acordo com os entrevistados, o ponto forte dessa experiência e a premissa para realizar um trabalho construtivo em favor da cidadania. Isso não significa que, entre representantes dos serviços e porta-vozes do voluntariado, não existam também dificuldades, incompreensões, diferenças de linguagem e, às vezes, até mesmo conflitos. Mas a continuidade e a institucionalização da relação favorecem - segundo a opinião dos informantes - a compreensão recíproca, o crescimento de todos os atores envolvidos no processo e a criação de relações de confiança que, em último caso, facilitam a análise e a resolução dos problemas. Esse empenho comum reforça o confronto e o diálogo entre os diversos segmentos dos comitês. Tal integração é, porém, possível por uma parte, se a estrutura sanitária renuncia, como refere um dirigente, "à sua tradicional atitude auto-referencial" e, por outra, se os representantes dos usuários evitam - como assinala um porta-voz dos usuários - aquele comportamento típico "de quem pressupõe que as próprias instâncias devam ser acolhidas sempre e de qualquer modo".

\section{Participação das associações nos Comitês Consultivos Mistos}

O nível de participação dos representantes das organizações de voluntários e de tutela dos direitos dos pacientes emergiu como um aspecto problemático dos CCM. A maioria dos nossos interlocutores, seja dos porta-vozes dos usuários seja dos profissionais e gerentes, evidenciou uma tendência à diminuição da participação, depois de uma primeira fase em que ocorreu uma ampla adesão das associações locais. Diversos são os motivos para explicar o decréscimo de participação: (a) antes de tudo, o "tempo" e o "empenho" que requerem as atividades a se desenvolverem no âmbito dos CCM. Estamos, naturalmente, falando de voluntários que já dedicam uma parte significativa de seu tempo à própria associação; (b) vários interlocutores, sobretudo das associações, identificaram, como possível fator de desmotivação, a limitada influência exercida pelos CCMs: "às vezes se tem a impressão de que o trabalho feito não en- 
contra resposta, não encontra uma resolução imediata"; (c) outro aspecto que pode ser relacionado a crises de participação dos comitês é a não adequada preparação dos voluntários chamados a desenvolver um papel complexo e bastante compromissado.

A voz dos comitês influi sobre os processos de decisão dos responsáveis dos serviços?

A participação implica, necessariamente, a capacidade de influir, direta ou indiretamente, junto a um processo público decisório 11 . No primeiro contato com o tema, um número significativo de porta-vozes dos usuários manifestou uma tendência a problematizar a relação com a contraparte colocando em relevo a limitada incidência de suas propostas. Numa sondagem posterior, solicitados a ilustrar com exemplos específicos aquilo que têm efetivamente obtido, revelou-se uma situação menos negativa. A maioria deles enumerou uma série de propostas aceitas e incorporadas aos processos de gestão. Entretanto, tais resultados têm exigido um notável investimento de energias por parte dos representantes do voluntariado. Um dado comum, surgido em todas as entrevistas, relaciona-se aos tempo - "exageradamente longo" - que as autoridades sanitárias empregam para pôr em ação essas recomendações. Naturalmente, como observam alguns representantes das associações, isso cria "ceticismo e desconfiança” e, talvez, a nosso ver, poderia ajudar a decifrar aquela atitude um pouco pessimista referente ao impacto da própria ação supra mencionada.

\section{Representatividade dos Comitês Consultivos Mistos}

Outro aspecto problemático já levantado por outras pesquisas em nível internacional referese à representatividade dos órgãos de tutela dos direitos dos pacientes 5,9,15. No caso dos CCM, registrou-se um amplo consenso entre os entrevistados sobre o fato de que os Comitês enfrentam questões que interessam aos usuários em geral. Segundo alguns entrevistados, existe, também, um risco de auto-referência das diferentes associações, sobretudo daquelas portadoras de doenças graves, mesmo que a experiência dos últimos anos tenha mostrado que os CCM conseguiram construir um espaço autônomo para operar como um fórum representativo dos direitos de todos os cidadãos e não somente de algumas categorias. Entretanto, o reconhecimento da amplitude e da profundidade das ações do CCM não implica que os CCM representem, formalmente, todos os usuários dos serviços. De fato, os entrevistados reconheceram as dificuldades dos CCM para entrar em contato com setores mais amplos da população.

\section{A participação dos cidadãos no serviço sanitário britânico}

\section{Transformações do National Health \\ Service e repercussões sobre os Conselhos Comunitários de Saúde}

O National Health Service britânico (Serviço Nacional de Saúde - NHS), instituído em 1948 sob a direção do Ministério da Saúde, tem sido submetido, desde sua criação, a uma constante tensão entre ser responsável diante da autoridade central ou ser responsável diante da comunidade local 16. Sucessivas reorganizações do NHS intentaram reduzir essa tensão que se foi acentuando ao longo dos anos 60 em conseqüência dos protestos dos movimentos de mulheres e dos grupos de auto-ajuda que questionavam a maneira como vinham sendo gerenciados os serviços. Em conseqüência de tais disfunções e denúncias, em 1974, foram instituídos os CHC, como instâncias de promoção e tutela dos interesses dos cidadãos.

Com a chegada do Partido Conservador (Conservative Party) ao Governo, a partir do começo dos anos 80 , inicia-se um processo de reforma do NHS, associado a uma cada vez maior importância dada ao papel do paciente, entendido como consumidor de serviços de saúde. O projeto do governo conservador (National Health Service and Community Care Act de 1990) efetivou uma radical mudança estrutural. A ascensão da aproximação consumista foi acompanhada, como sublinham Lupton et al. 17, de uma atitude de "prevenção e suspeita" em direção às formas tradicionais de participação ativa dos cidadãos. O novo governo trabalhista, eleito em 1997 para restabelecer a confiança dos cidadãos no NHS, relançou o modelo da "terceira via", entre o modelo centralista e o modelo de inspiração neoliberal. A competição foi substituída pela cooperação 18 . Em 2001, o segundo governo trabalhista publica o documento Involving Patients and the Public in Healthcare, em que propõe a extinção dos CHC e sua substituição por uma série de novos órgãos de representação dos interesses dos cidadãos. A aproximação conflituosa e reivindicativa dos CHC não era mais adequada à nova filosofia trabalhista centrada na partnership e na responsabilização das autoridades locais 19 . 


\section{Resultados de uma investigação sobre os Conselhos Comunitários de Saúde}

O objetivo de nosso estudo é analisar esse foro de participação social, examinando sua longa e consolidada experiência de representação dos interesses dos cidadãos. A pesquisa foi realizada na Inglaterra e abrangeu cinco distritos sanitários da região de Londres, o distrito de $\mathrm{Ox}$ fordshire, o de East Berkshire e o distrito da região de Medway \& Swale. Foram efetuadas 22 entrevistas com diretores dos CHC (representantes dos usuários), profissionais e gerentes das unidades de saúde. Foram realizadas, também, observações diretas durante algumas reuniões dos CHC. Referimos, em seguida, os resultados do estudo organizados nas seguintes quatro áreas temáticas: (a) organização e funcionamento dos CHC; (b) representatividade; (c) nível de participação; (d) influência dos CHC sobre as autoridades sanitárias.

\section{Modelos organizativos e funcionamento} dos Conselhos Comunitários de Saúde

Os CHC estão presentes em cada distrito sanitário e são formados por um mínimo de $24 \mathrm{e}$ um máximo de 30 membros, segundo o número de habitantes do distrito. A metade dos membros é nomeada pelas autoridades locais; um terço é eleito pelas organizações de voluntariado e um sexto é nomeado pelas autoridades sanitárias regionais. São voluntários e têm direito a receber, unicamente, um reembolso de gastos. Os CHC devem reunir-se pelo menos três vezes ao ano, embora geralmente se reúnam, conforme a declaração dos entrevistados, uma vez a cada dois meses.

Pode-se dizer que o elemento que mais caracteriza os $\mathrm{CHC}$, em relação a outros foros de participação em saúde, é o fato de serem formados unicamente por representantes dos usuários. Os CHC, tendo uma função de controle, podem inspecionar livremente todas as unidades de saúde. Em outras palavras, tratase de um instrumento essencialmente reivindicativo, com escassas possibilidades de interação e diálogo com os profissionais e gerentes dos serviços de saúde. Todavia o fato de serem independentes tanto da administração dos serviços como das autoridades políticas locais representa, na opinião dos informantes, o aspecto mais qualificado dos CHC, já que logra dar segurança e confiança aos pacientes que têm vivenciado experiências negativas. A independência (ou seja, o papel de "watchdog", para enfatizar seu papel de controladores externos do sistema sanitário) é considerada um bem precioso que, como afirma um informante, "torna possível criticar o que não funciona".

\section{Representatividade dos Conselhos Comunitários de Saúde}

Um aspecto crítico, já evidenciado por outras investigações realizadas sobre os CHC, é a representatividade 17,20. Com efeito, os CHC têm sido freqüentemente objeto de críticas por não lograrem representar alguns grupos sociais e determinadas necessidades sócio-sanitárias da população. Os usuários portadores de deficiências físicas e com problemas mentais, os pensionistas e, no geral, os segmentos de população com um baixo nível de renda estão insuficientemente representados nos CHC. Os jovens (tanto homens como mulheres) também estão escassamente representados, assim como as diversas minorias étnicas e os grupos de imigrados. Os CHC estão, na sua maioria, formados, enfatiza um informante, por representantes da "classe média, de origem branca e adultos". Os mesmos diretores dos CHC entrevistados reconheceram as dificuldades para representar os interesses de toda a cidadania.

\section{Nível de participação}

O problema da representatividade está estreitamente relacionado com o da participação; nesse sentido, nossa pesquisa revelou uma escassa tendência de participar por parte de alguns setores da população, como os jovens e os grupos étnicos. Existe um consenso entre todos os informantes de identificarem, nos membros nomeados pelas autoridades locais $(50 \%$ do total), a categoria de representantes com menor presença e compromisso no trabalho desenvolvido pelos $\mathrm{CHC}$.

É ainda importante assinalar uma posição bastante difundida entre os diretores dos $\mathrm{CHC}$, segundo os quais é preciso abandonar os esquemas tradicionais até agora utilizados para comprometer o público e adotar estratégias mais flexíveis e criativas. Uma dessas estratégias, já experimentada pelos entrevistados, é de entrar diretamente em contato com associações e grupos organizados, indo ao seu território e aos lugares onde se reúnem.

\section{Influência dos Conselhos Comunitários de Saúde sobre as autoridades sanitárias}

Diversas pesquisas realizadas no Reino Unido mostraram que a voz dos usuários freqüentemente exerce um impacto bastante limitado sobre as deliberações das autoridades de saú- 
de, que geralmente são determinadas por outros fatores 3,21. Os resultados da nossa investigação evidenciaram, igualmente, uma situação bastante problemática no que diz respeito à capacidade dos CHC de incidir sobre os gerentes dos serviços. Alguns informantes chegaram a criticar, com determinação, a atitude dos dirigentes dos serviços, sublinhando tanto " $a$ retórica do envolvimento dos pacientes" - continuamente reiterada em todos os discursos políticos - como a "escassa atenção em recolher as necessidades e propostas provenientes dos representantes dos usuários".

\section{A participação dos cidadãos no Sistema Único de Saúde do Brasil}

\section{Evolução do sistema sanitário}

Antes da reforma constitucional de 1988, o sistema de saúde brasileiro era fortemente centralizado e mostrava pouca atenção às atividades de prevenção e de assistência sanitária de base 22. Em 1986, realizou-se a VIII Conferência Nacional de Saúde, um evento de grande relevância nacional, que mobilizou amplos setores da sociedade civil 7. A Constituição Federal de 1988 incorporou grande parte das propostas elaboradas pela Conferência e instituiu o Sistema Único de Saúde (SUS). Em 1990, foram publicadas Leis (8.080 e 8.142) para implementar o SUS e seus princípios fundamentais. Como instância de participação da população, foram criados os Conselhos de Saúde e as Conferências de Saúde.

\section{Objetivos e característica organizativas dos Conselhos Municipais de Saúde}

Segundo a Lei Orgânica da Saúde, os Conselhos de Saúde "atuam na formulação de estratégias de política de saúde e no controle da execução das políticas (...) ocupando-se também de aspectos econômicos e financeiros" 23 (p. 16). A lei estabelece o caráter permanente e deliberativo desses órgãos. A instância de participação em nível municipal é representada pelos CMS. São integrados por representantes do governo, dos prestadores de serviços particulares ou sem fim lucrativos, dos representantes dos profissionais e dos usuários. Esses últimos dispõem da metade dos representantes; a outra metade é repartida entre os membros das outras categorias.

A nosso ver, a peculiaridade do Conselho de Saúde é ser deliberativo, ou seja, participa diretamente no processo de tomada de decisão.
Esta característica diferencia o sistema de participação brasileiro da maioria das experiências internacionais.

\section{A experiência dos Conselhos Municipais de Saúde}

Para fazer um balanço da experiência dos CMS, utilizamos os resultados de uma pesquisa realizada no Estado do Ceará, que foram complementados, em algum aspecto relevante da análise, por outros estudos de abrangência nacional ou efetuados em nível estadual (Bahia, Ceará e Santa Catarina). A nossa pesquisa, que adotou o método do estudo de caso, foi realizada em dois municípios do Estado do Ceará no ano 2002 24. O estudo foi implementado pela aplicação de entrevistas semi-estruturadas aos principais atores que agem no CMS dos dois municípios pesquisados: (a) representantes de usuários (12); (b) representantes de profissionais (4); (c) representantes de prestadores de serviços particulares (4); (d) secretários de saúde (2). Além da entrevista, foram analisadas as atas dos CMS referentes aos anos 1999 e 2000 e foi efetuada uma observação direta de algumas reuniões dos conselhos estudados (6). Em seguida, apresentaremos os resultados, organizados nos seguintes quatro conteúdos: (a) potencialidades dos CMS; (b) representatividade; (c) desigualdade de informação entre os representantes dos diferentes segmentos; (d) nível de influência no processo de tomada de decisões.

\section{Potencialidades dos Conselhos Municipais de Saúde}

Em primeiro lugar, a pesquisa registrou um amplo consenso de todos os atores envolvidos sobre a importância e o valor social desse fórum de participação dos cidadãos no âmbito da saúde. Trata-se, na visão dos informantes, de um espaço social "democrático", "aberto à comunidade" e "descentralizado", cujo objetivo é facilitar o acesso da população, tanto urbana quanto rural, ao processo de discussão e deliberação sobre assuntos referentes à saúde coletiva. A maioria dos conselheiros entrevistados considera a dinâmica das reuniões do CMS satisfatória por apresentarem "diversidade de opiniões" e "riquezas em suas discussões”, podendo favorecer o "entrosamento" e o "crescimento dos participantes".

Apesar dos significativos avanços alcançados, os entrevistados assinalaram alguns impasses no funcionamento e no nível de atuação desse fórum de participação social. 


\section{Representatividade}

A comunicação entre CMS e comunidade tem sido apontada como um importante aspecto a ser aprimorado para incrementar o grau de representatividade desse foro de participação. Nos dois casos cearenses, a maioria dos conselheiros entrevistados afirmou ser necessário estabelecer uma relação com a comunidade, tanto anterior quanto posterior às reuniões do CMS, com o objetivo de identificar as prioridades da comunidade, bem como repassar as discussões e decisões tomadas nas reuniões. Porém vale ressaltar que essa identificação de problemas e o repasse de informações são realizados de "maneira informal", isto é, depende da "boa vontade" do conselheiro estabelecer ou não uma relação contínua com o segmento por ele representado. Contudo a existência de uma estrutura mais ágil que pudesse apoiar o trabalho do conselho representaria - como reconhecem também os gestores e os profissionais entrevistados - um pré-requisito essencial para poder estabelecer uma relação mais estreita entre conselheiros e comunidade.

Outras duas pesquisas - uma de abrangência nacional 25 e uma efetuada na Região Metropolitana do Rio de Janeiro 26 - tinham já tornado evidente a mesma questão da representatividade.

\section{Desigualdade de informação entre os representantes dos diversos segmentos do Conselho Municipal de Saúde}

A concentração das informações nos gestores e nos técnicos, que acabam influenciando as decisões do CMS, é uma constante preocupação que tem aflorado durante todo o processo de investigação. De fato, vários entrevistados salientaram que a participação dos conselheiros usuários "é ainda tímida", visto que a maioria não possui uma qualificação adequada para poder contribuir na análise e na resolução dos temas discutidos nas reuniões, ficando, portanto, muitas vezes, "alheio ao debate" e não "expressando a própria voz”. Essa situação descrita não põe em dúvida o grau de participação dos conselheiros usuários nas reuniões - que é considerado de bom nível, ao contrário de outra experiência internacional em saúde - mas a qualidade dessa participação. Reconhece-se, como já tinham evidenciado outros estudos realizados no Ceará 27,28 , a dificuldade dos conselheiros usuários de aportar suas próprias experiências e percepções no processo de identificação de prioridades e avaliação dos serviços.

Estes resultados se encontram em consonância com outros estudos nacionais. Uma pes- quisa, realizada em municípios de diferentes portes e em diversas regiões do país, por exemplo, apontou como questão crítica referente à atuação dos CMS o nível de autonomia e independência dos representantes dos usuários “em relação ao saber e poder médicos, geralmente centralizado na figura do secretário de saúde..." 25 (p. 93). Na mesma linha, encaixam-se os resultados da pesquisa de Wendhausen \& Caponi 29, realizada em um Conselho de Saúde de um município catarinense, em que foi evidenciada uma relação assimétrica entre os conselheiros usuários e os demais representantes.

\section{A voz dos representantes}

da comunidade tem influência no

processo de tomada de decisões?

Uma direta conseqüência da desigualdade de informação entre os diferentes atores que integram o CMS é a dificuldade de os representantes dos usuários expressarem sua voz para poderem influenciar as deliberações do conselho. Como observam alguns informantes, existe uma tendência a uma abordagem técnica nas discussões dos CMS, em que prevalece "uma fala muito recheada de tecnicismo" e "pouca praticidade dos assuntos debatidos”. Essa prática, nota um entrevistado, contribui para "silenciar os conselheiros de saúde do segmento dos usuários, porque eles nem sempre conhecem esse vocabulário". Na opinião de outro informante, a hegemonia da linguagem técnica dos gestores e dos profissionais é o resultado da prática dos Conselhos de enfocar, particularmente, discussões sobre aspectos técnicos e setoriais dos serviços de saúde, ao invés de dedicar mais tempo ao debate de políticas de saúde que poderiam ter um impacto positivo nos indicadores sociais da população.

Resultados semelhantes foram evidenciados em pesquisas realizadas nos Estados da Bahia 30 e do Rio de Janeiro 26. O estudo de Labra \& Figuereido 26 , por exemplo, demonstra que os conselheiros-usuários ainda exercem uma influência parcial sobre as decisões do presidente do CMS.

\section{Análise comparativa dos três sistemas de participação}

Com base nos resultados das pesquisas realizadas nos três países, propomo-nos a reler algumas classificações teóricas presentes na literatura especializada sobre participação em saúde com intuito de aprofundar e problematizar algumas categorias de análise utilizadas nesse setor. Para esse fim, analisaremos as seguintes 
três dimensões da participação em saúde: (a) organização e composição dos órgãos colegiados; (b) papel dos porta-vozes dos cidadãos; (c) tipo de abordagem da participação prevista no sistema de saúde.

No que diz respeito à organização, podemos traçar uma primeira diferença entre os fóruns mistos, ou seja, compostos por usuários, profissionais e gerentes, como os colegiados da Itália e do Brasil e aqueles formados somente por representantes dos usuários, como no caso dos CHC da Inglaterra. O sistema misto parece-nos estrategicamente mais vantajoso, uma vez que favorece a integração dos diferentes "backgrounds" profissionais, perspectivas de análise e experiências, além de representar uma boa estratégia para aumentar as possibilidades de influir nos gerentes dos serviços. Nesse sentido, o modelo misto privilegia um processo dialético e a criação de práxis e canais de comunicação entre os diferentes atores, a fim de contribuir na elaboração de objetivos coletivos, favorecendo, por conseguinte, a construção de um projeto de cidadania ativa.

Analisando o papel desenvolvido pelos três fóruns e a relação que mantêm com as autoridades de saúde, surge outra diferença significativa. Os CMS são deliberativos, ou seja, coparticipam diretamente nos processos de tomada de decisões. Os CCM são consultivos. Os CHC são eminentemente órgãos independentes e de controle. Logo, à primeira vista, a verdadeira discriminante é o fato de serem admitidos na mesa em que são tomadas as decisões. Entretanto, não podemos nos deter na análise normativa, pois o exame da organização formal das três instâncias de representação dos cidadãos é somente uma premissa. De fato, é importante, também, averiguar, por intermédio de investigações pontuais, a existência de práxis de participação consolidada. A experiência brasileira, por exemplo, não tem demonstrado, até hoje, que existam significativas vantagens pelo fato de os conselheiros usuários participarem num fórum com caráter deliberativo. Realmente, os porta-vozes dos cidadãos nos CMS, como evidenciaram as diversas pesquisas apresentadas, encontram-se numa posição de desvantagem em relação aos representantes dos outros segmentos. Vice-versa, os CCM, ainda que não exerçam um papel deliberativo, têm desenvolvido razoáveis capacidades de propostas e de controle da qualidade dos serviços de saúde e têm exercido, pelo menos nos primeiros cinco anos de existência, uma apreciável influência nos gerentes.

Sobre esse ponto - deliberativo ou consultivo - o debate é ainda muito vivaz. Segundo vários autores 3,6,31, a participação dos cidadãos implica um processo de co-participação nas tomadas de decisões. Habermas 32 não é da mesma opinião; segundo ele, a formação da opinião pública fica descolada dos processos de tomada de decisões. Para Habermas 32 , as associações da sociedade civil, por meio das esferas públicas, podem somente exercer uma influência sobre o sistema para tentar modificar as estratégias pelas quais são enfrentados os problemas, mas não podem participar diretamente das decisões. No entanto, o modelo de esfera pública do autor alemão tem recebido várias críticas. Segundo Fraser 33, a concepção habermasiana de esfera pública supõe uma separação clara entre associações da sociedade civil e Estado, e isso tem como conseqüência o fato de reconhecer a existência de "públicos débeis" cuja prática deliberativa consiste, unicamente, na formação de opinião sem incluir a possibilidade de tomar, efetivamente, decisões. Na mesma direção, Cook 34 afirma que, segundo Habermas, a sociedade civil pode ter, unicamente, uma influência indireta sobre a autotransformação do sistema político, já que os cidadãos são relegados à periferia dos processos de decisão. Essas são somente algumas posições de uma discussão ainda não acabada.

Uma característica comum às três instâncias de participação estudadas refere-se ao tipo de abordagem adotado pelo sistema de saúde na relação com os cidadãos. Os usuários dos serviços de saúde são reconhecidos, não como simples indivíduos, mas como cidadãos portadores de uma visão coletiva que participam plenamente nos processos de decisão das instituições de saúde. Essa aproximação coletiva não é um aspecto secundário em um período dominado pelas filosofias "consumistas", em que os serviços de saúde são programados para responder às demandas e às preferências dos clientes ${ }^{3}$. Com efeito, a participação assume diferentes significados e implica diversas concepções filosóficas acerca da relação entre estado e sociedade civil e, no caso específico, entre sistema de saúde e usuários. Tais diferenças são ilustradas pela mesma terminologia usada para definir as pessoas que utilizam o serviço: consumidor, cliente, paciente, usuário, cidadão etc. Existe a visão tipo "supermarket", segundo a qual a atenção à saúde pode melhorar somente na presença de um livre mercado em que os consumidores, individualmente, têm a plena liberdade de escolher entre os vários produtos disponíveis nas prateleiras; existe, porém, a visão que advoga o envolvimento ativo do cidadão no processo de produção da saúde. Nessa segunda direção, inserem-se os fóruns 
de participação analisados que, apesar das limitações identificadas, têm possibilitado superar a reduzida abordagem individualista.

\section{Conclusões}

Como conclusão, gostaríamos de abordar brevemente dois pontos críticos que surgiram nas três experiências analisadas. Em primeiro lugar, o problema da representatividade. Não se pode falar de representatividade no sentido próprio do termo, por não existirem mecanismos formais de delegação por intermédio dos quais grupos ou categorias de usuários elejam seus representantes. Além disso, é difícil argumentar que tais fóruns possam representar a todos os cidadãos de uma determinada área ou a todos os usuários de um serviço, considerando a limitada proporção de pessoas que participam ativamente. Por outro lado, é também árduo falar de representatividade frente a um fenômeno social baseado completamente no trabalho voluntário. Trata-se, sem dúvida, de uma representação socialmente relevante, baseada no significativo papel desenvolvido por esses fóruns e no importante valor de sua ação voluntária.

Outro aspecto crítico se refere à capacidade dos porta-vozes dos cidadãos de exercerem sua influência nos processos de tomada de decisões dos gestores. Apesar de alguns resultados positivos obtidos pelas instâncias de participação analisadas, temos observado a persistência de certas práticas e atitudes dos sistemas de saúde ainda um pouco auto-referenciais. Isso representa, segundo os relatos dos representantes dos usuários, um fator de desmotivação e de afastamento dos porta-vozes da comunidade e das associações que não logram ver reconhecido o valor da própria ação. Contudo, há quem - sobretudo na visão de gerentes e profissionais - inverta essa relação de dependência entre poder de decisão dos órgãos colegiados e nível de participação, alegando que conselhos fortes e mais representativos das comunidades locais conseguiriam, também, mobilizar e implicar um número maior de portavozes dos cidadãos no processo de negociação com os gerentes e, por conseqüência, exerceriam uma maior pressão e influência. Em outras palavras, estamos diante de sistemas sanitários auto-referenciais e ainda incapazes de confrontar-se com seus ambientes sociais, ou diante de uma sociedade civil ainda débil e desorganizada, que, até agora, não tem conseguido expressar formas adequadas de protagonismo social e de participação, para aproveitar as pequenas aberturas proporcionadas pelos sistemas de saúde? Talvez ambas as hipóteses sejam certas. Como explicar, de outra forma, a insensibilidade da gerência em relação a algumas propostas de melhora da qualidade da atenção que não comportavam grandes investimentos financeiros ou reorganizações radicais do sistema de saúde? Ou, como é possível entender o fato de que a rede de voluntariado sanitário, sobretudo onde está tradicionalmente arraigada, não esteja ainda em condição de garantir uma adequada participação nos Conselhos e Comitês de Saúde?

Pelos resultados das análises empíricas efetuadas nos três países, pode-se recomendar aos órgãos de representação dos interesses dos cidadãos - deliberativos, consultivos ou propositivos - instaurar relações mais intensas e significativas com a própria base de apoio; estar presentes tanto nas instituições sanitárias como na comunidade; escutar a voz dos pacientes; levantar as necessidades dos usuários e as falhas do sistema dos serviços. Dessa forma, os fóruns poderiam reforçar sua representatividade e conseguir exercer uma maior influência. Deveriam, em outras palavras, desenvolver um modelo de participação que trouxesse sua legitimação, ação e força contratual da relação intensa com os cidadãos 15. Assim, parece-nos interessante concluir com as recomendações do Ministério da Saúde brasileiro 35 que oportunamente enfatiza a necessidade de os conselheiros conquistarem a adesão e mobilização dos segmentos representados: "as deliberações [dos Conselhos de Saúde] somente terão poder de mudança para a construção do SUS, na medida em que as entidades priorizem, na suas agendas de pressões e mobilizações, as deliberações dos Conselhos" 35 (p. 61). 


\section{Resumo}

O artigo apresenta três modelos de participação em saúde - os Comitês Consultivos Mistos da Itália, os Conselhos Comunitários de Saúde da Inglaterra e os Conselhos Municipais de Saúde do Brasil - evidenciando as potencialidades, os aspectos organizacionais e as debilidades de cada um. Sucessivamente, fazse uma análise comparativa das três experiências, destacando regularidade e variações em relação às principais características da participação em saúde. Os resultados da pesquisa apontam para a discussão de algumas categorias teóricas presentes na literatura especializada no campo da participação em saúde. Precisamente, analisam-se as seguintes dimensões da participação: (a) organização e composição dos fóruns de participação; (b) papel desempenhado pelos representantes dos cidadãos (consultivo, deliberativo ou de controle); (c) tipo de aproximação (individual ou coletiva) de participação em saúde. Finalmente, o artigo enfoca dois pontos críticos surgidos nas três experiências de participação e, precisamente, o problema da representatividade das instâncias colegiadas e a dificuldade dos porta-vozes dos cidadãos de exercerem sua influência nos processos de tomada de decisões dos gestores.

Participação Cidadã; Sistemas de Saúde; Comitês Consultivos

\section{Colaboradores}

M. Serapioni participou de todas as etapas de elaboração do artigo, desde o delineamento do estudo, a coleta e análise das informações até a redação final. O. Romaní colaborou com a discussão dos resultados e com a revisão crítica final do artigo.

\section{Agradecimentos}

À Fundação Cearense de Apoio ao Desenvolvimento Científico e Tecnológico pela bolsa concedida ao autor Mauro Serapioni.

\section{Referências}

1. Buss PM, Labra ME, organizadores. Sistemas de saúde: continuidades e mudanças. Rio de Janeiro: Editora Hucitec; 1995.

2. Trabucchi M, organizador. I cittadini e il sistema sanitario nazionale. Dalla qualità percepita all'impegno per il cambiamento. Bolonha: Il Mulino; 1996.

3. Milewa T, Valentine J, Calnan M. Managerialism and active citizenship in Britain's reformed health service. Soc Sci Med 1998; 4:507-17.

4. Ugalde A. Ideological dimension of community participation in Latin American health programs. Soc Sci Med 1985; 1:53.

5. Zakus D, Lysack C. Revisiting community participation. Health Policy Plan 1998; 1:1-12.

6. Arnstein S. A ladder of community participation. J Am Inst Plann 1969; 35:216-24.

7. Carvalho AI. Conselhos de saúde no Brasil: participação cidadã e controle social. Rio de Janeiro: Instituto Brasileiro de Administração Municipal/ FASE; 1995.

8. Cortes SM. Conselhos municipais de saúde: a possibilidade dos usuários participarem e os determinantes da participação. Ciênc Saúde Coletiva 1998; 1:5-17.

9. Crouch C. La ampliación de la ciudadanía social y económica y la participación. In: García S, Lukes S, organizadores. Ciudadanía, justicia social, identidad y participación. Madrid: Siglo Veintiuno; 1999. p. 257-85.

10. Pollock AM. Local voices: the bankrupcy of the democratic process. BMJ 1992; 6853:535-6.

11. Ardigò A. Società e salute: lineamenti di sociologia sanitaria. Milano: Angeli; 1997.

12. Cipolla C. Epistemologia della tolleranza. Milano: Angeli; 1997.

13. Giarelli G. Il malessere della medicina: un confronto internazionale. Milano: Angeli; 2003.

14. Hanau C, Gattei L. I comitati consultivi misti nell'Azienda Sanitaria di Bologna. L’Arco di Giano 1998; 16:180-92.

15. Altieri L. Verso una valutazione come negoziazione in un pluralismo di valori. In: Cipolla C, Giarelli G, Altieri L, organizadores. Valutare la qualità in sanità: approcci, metodologie e strumenti. Milano: Angeli; 2002. p. 95-126.

16. Klein R. Looking after consumers in the new NHS. BMJ 1990; 6736:1351-2.

17. Lupton C, Peckam S, Taylor P. Managing public involment in healthcare purchasing. Buckingham: Open University Press; 1998.

18. Department of Health. The new NHS: modern dependable. London: The Stationary Office; 1997.

19. Department of Health. Involving patients and the public in healthcare. London: The Stationary Office; 2001.

20. Pickard S. The future organization of Community Health Councils. Social Policy \& Administration 1997; 3:274-89.

21. Rhodes P, Nocon A. User involvement and the NHS reforms. Health Expect 1998; 2:73-81.

22. Neto ER. A reforma sanitária e o Sistema Único de Saúde. In: Ministério da Saúde, organizador. Incentivo à participação popular e ao controle 
social do SUS. Brasília: Ministério da Saúde; 1994. p. 7-17.

23. Ministério da Saúde. Conselhos de saúde: guia de referência para a sua criação e organização. Brasília: Ministério da Saúde; 1993.

24. Serapioni M, Silva VA. Potencialidades e limites dos Conselhos Municipais do Ceará: dois estudos de caso. Fortaleza: Escola de Saúde Pública do Ceará; 2002.

25. Pessotto UC, Nascimento PR, Heimann LS. A gestão semiplena e a participação popular na administração da saúde. Cad Saúde Pública 2001; 17:89-97.

26. Labra ME, Figueiredo J. Associativismo, participação e cultura cívica. O potencial dos conselhos de saúde. Ciênc Saúde Coletiva 2002; 3:537-47.

27. Cordeiro C, organizador. Os conselhos de saúde no Ceará e os desafios da capacitação. Fortaleza: Escola de Saúde Pública do Ceará; 1997.

28. Noronha RW. O conselho municipal de saúde de Baturité: participação popular e controle social [Dissertação de Mestrado]. Fortaleza: Centro de Ciência da Saúde, Universidade Estadual do Ceará; 1994.
29. Wendhausen A, Caponi S. O diálogo e a participação em um conselho de saúde em Santa Catarina, Brasil. Cad Saúde Pública 2002; 18:1621-8.

30. Oliveira TD, Molesini JO, Gomes IF, Teixeira CF Conselhos municipais de saúde na Bahia: avaliação dos resultados da capacitação de conselheiros de saúde. Rev Baiana Saúde Pública 1999; 1/4: 75-98.

31. De Roux GI. Participación y cogestión de la salud. Educ Med Salud 1993; 1:50-60.

32. Habermas J. Fatti e norme. contributi a una teoria discorsiva del diritto e della democrazia. Milano: Guerini Associati; 1996.

33. Fraser N. Rethinking the public sphere: a contribution to the critique of actually existing democracy. In: Calhoun C, editor. Habermas and the public sphere. Cambridge: The MIT Press; 1992. p. 109-36.

34. Cook D. The talking cure in Habermas's republic. New Left Rev 2001; 12:135-51.

35. Ministério da Saúde. Gestão municipal de saúde: textos básicos. Brasília: Ministério da Saúde; 2001.

Recebido em 05/Abr/2004

Versão final reapresentada em 27/Dez/2005

Aprovado em 21/Fev/2006 